\title{
Hollow Ceramic Microspheres Prepared by Combining Electro-spraying with Non-solvent Induced Phase Separation Method: A Promising Feedstock for Thermal Barrier Coatings
}

\section{DOI:}

10.1016/j.matdes.2017.11.022

\section{Document Version}

Accepted author manuscript

Link to publication record in Manchester Research Explorer

\section{Citation for published version (APA):}

Xiao, P., \& al, E. (2018). Hollow Ceramic Microspheres Prepared by Combining Electro-spraying with Non-solvent Induced Phase Separation Method: A Promising Feedstock for Thermal Barrier Coatings. Materials \& Design, 139, 343-350. https://doi.org/10.1016/j.matdes.2017.11.022

\section{Published in:}

Materials \& Design

\section{Citing this paper}

Please note that where the full-text provided on Manchester Research Explorer is the Author Accepted Manuscript or Proof version this may differ from the final Published version. If citing, it is advised that you check and use the publisher's definitive version.

\section{General rights}

Copyright and moral rights for the publications made accessible in the Research Explorer are retained by the authors and/or other copyright owners and it is a condition of accessing publications that users recognise and abide by the legal requirements associated with these rights.

\section{Takedown policy}

If you believe that this document breaches copyright please refer to the University of Manchester's Takedown Procedures [http://man.ac.uk/04Y6Bo] or contact uml.scholarlycommunications@manchester.ac.uk providing relevant details, so we can investigate your claim.

\section{OPEN ACCESS}




\section{Accepted Manuscript}

Hollow ceramic microspheres prepared by combining electrospraying with non-solvent induced phase separation method: A promising feedstock for thermal barrier coatings

Fangwei Guo, Xing Chen, Guowei Wang, Zouzhong Hua, Xin Wang, Qin Zhang, Xiaofeng Zhao, Ping Xiao

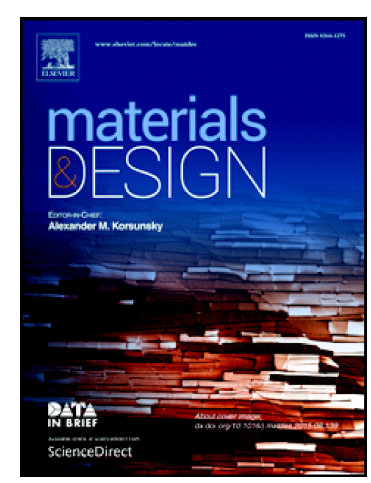

PII: S0264-1275(17)31053-5

DOI: doi:10.1016/j.matdes.2017.11.022

Reference: JMADE 3499

To appear in: Materials \& Design

Received date:

7 July 2017

Revised date: 10 November 2017

Accepted date: 10 November 2017

Please cite this article as: Fangwei Guo, Xing Chen, Guowei Wang, Zouzhong Hua, Xin Wang, Qin Zhang, Xiaofeng Zhao, Ping Xiao , Hollow ceramic microspheres prepared by combining electro-spraying with non-solvent induced phase separation method: A promising feedstock for thermal barrier coatings. The address for the corresponding author was captured as affiliation for all authors. Please check if appropriate. Jmade(2017), doi:10.1016/j.matdes.2017.11.022

This is a PDF file of an unedited manuscript that has been accepted for publication. As a service to our customers we are providing this early version of the manuscript. The manuscript will undergo copyediting, typesetting, and review of the resulting proof before it is published in its final form. Please note that during the production process errors may be discovered which could affect the content, and all legal disclaimers that apply to the journal pertain. 


\section{Hollow Ceramic Microspheres Prepared by Combining}

\section{Electro-spraying with Non-solvent Induced Phase Separation}

\section{Method: A Promising Feedstock for Thermal Barrier Coatings}

Fangwei Guo ${ }^{a^{*}}$, Xing Chen ${ }^{a}$, Guowei Wang ${ }^{b}$, Zouzhong Hua ${ }^{a}$, Xin Wang ${ }^{c}$, Qin Zhang ${ }^{d}$, Xiaofeng Zhao ${ }^{a^{*}}$, Ping Xiao ${ }^{a, e}$

a School of Materials Science and Engineering, Shanghai Jiao Tong University, Shanghai 200240,

\section{China}

b China Nuclear Power Engineering \&Technology Co. Ltd., Shanghai 200240, China

c Konca Solar Energy Co. Ltd., Wuxi 214174, China

d Institute for Environmental Reference Materials Ministry of Environmental Protection,Beijing 100029, China

e School of Materials, University of Manchester, Manchester M13 9PL, United Kingdom 


\section{Graphical Abstract}

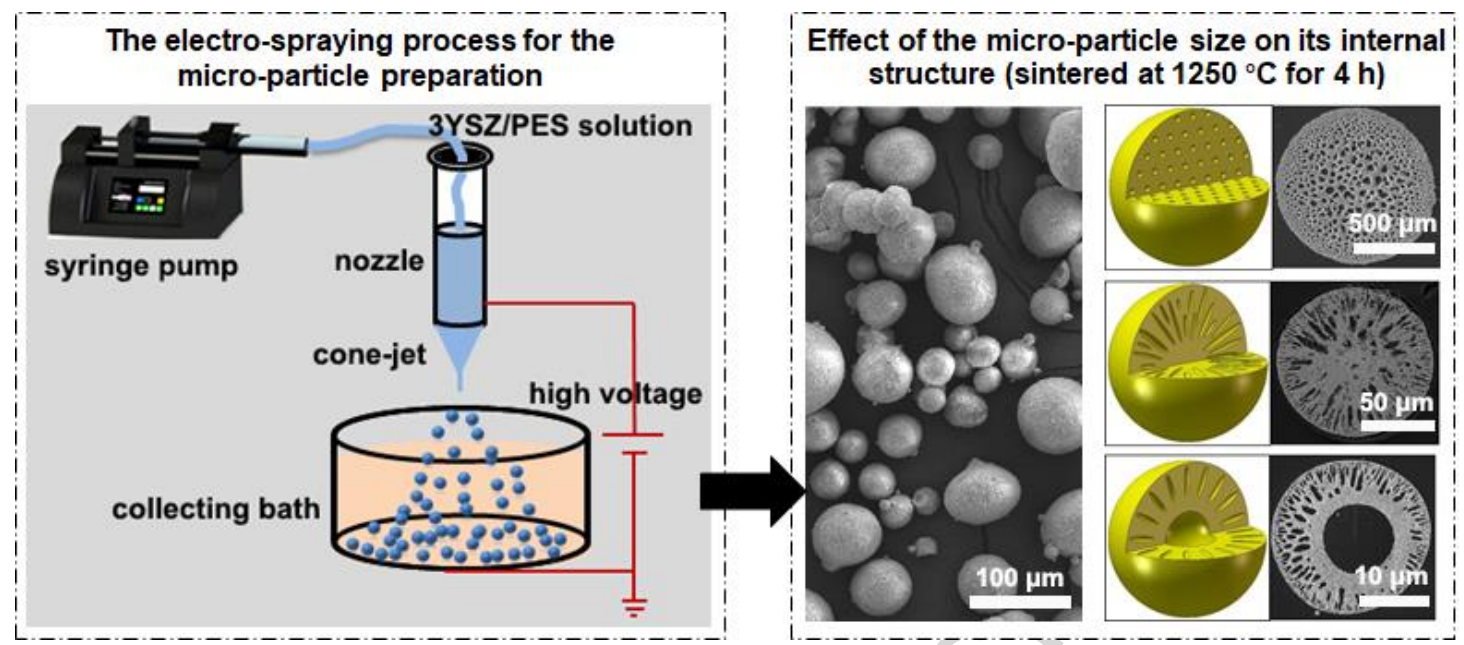




\begin{abstract}
Hollow microspheres were prepared by a combination method of electro-spraying and non-solvent induced phase separation, using a slurry of polymer with $\mathrm{Y}_{2} \mathrm{O}_{3}$-stabilized $\mathrm{ZrO}_{2}$ powder (YSZ). Subsequent sintering was carried out to obtain porous hollow YSZ microspheres with proper strength aiming to be thermal spraying feedstock. The ESNP particle size and distribution strongly depended on the applied voltage of the electro-spraying process and the jet nozzle diameter. The YSZ microspheres always consisted of a thin spongy shell and highly porous interior structure. The microsphere size decreased from 1000 to $100 \mu \mathrm{m}$ with increasing voltage $(10 \sim 20 \mathrm{kV})$. The cone-jet mode of electrospray reached steady as the nozzle diameter varied from 0.5 to $0.8 \mathrm{~mm}$. Compared with the coatings made from commercial hollow spherical powder, the coatings prepared by ESNP powder had enhanced resistance to sintering and exhibited a longer life than commercial spray powder. It has demonstrated that the ESNP method provides a versatile way to manipulate the microstructure of ceramic microspheres, and could been used to fabricate high performance thermal barrier coatings by plasma spraying.
\end{abstract}

Keywords: electro-spraying; non-solvent induced phase separation; yttria-stabilized zirconia microspheres; inner structure; sintering resistance 


\section{Introduction}

Air plasma sprayed thermal barrier coatings are widely used in the hot sections in the industrial gas turbines or aero engines to protect the metallic components from high temperature. It usually employs microspheres made of $\mathrm{Y}_{2} \mathrm{O}_{3}$-stabilized $\mathrm{ZrO}_{2}$ (7 8 wt. $\left.\% \mathrm{YO}_{1.5}\right)$ as feedstock powder, having sizes from several micrometers to more than 100 micrometers $[1,2]$. In addition to the processing parameters, the microstructure of YSZ microspheres is crucial to the performance (e.g., life and thermal conductivity) of the thermal barrier coatings (TBCs) [3-7]. Thus, a low cost, high performance YSZ feedstock is always desirable for the TBCs application. The morphology and microstructure of the feedstock powders were found to significantly affect the thermal properties (i.e. thermal conductivity and densification rate) of the TBC by way of changing the TBCs' microstructure [5, 8-10]. The coatings made from commercial hollow spherical powder (denoted by HOSP) were found to have lower thermal conductivity than that made from commercial fused and crushed powder (denoted by FC) [3-5, 8-10]. The reduction in thermal conductivity was believed to be caused by higher porosity. The study [5] also found that less densified coatings could accommodate more stress thus could achieve a long-term survival, which was probably owing to the nanostructures reserved [11-14]. Recently, the modified agglomerated-unsintered (AS) powder has been developed, which has homogenous nano-equiaxed structure that is able to produce uniform nanostructured and bimodal structured coatings with lower thermal conductivity and higher strain tolerance $[5,13$, 15]. However, questions have been raised about the possibility of accelerated sintering of the coatings made of these nanostructured YSZ powders. Therefore, it is anticipated that microspheres consisting of a hollow internal structure covered by a nanostructured porous shell with nanometer pores (like in the AS powder), when used as the thermal spray feedstock may help TBCs to achieve lower thermal conductivity and improved strain tolerance simultaneously.

The electro-spray processing is a versatile technique to prepare polymeric particles ranging from micrometer to nanometer, which has been widely employed as drug delivery carriers [16-18]. In this technique, a polymeric slurry (with or without solid) 
flows at a controlled rate under the influence of a high voltage gradient (several $\mathrm{kV}$ ) [17-22]. Using this technique to spray preceramic polymeric slurry enables fabricating ceramic particles with uniform porous microstructure [19]. However, the size of the obtained ceramic particles was in the millimeter scale that is not suitable for the thermally spray process [3-7]. Additionally, their morphology was irregular because of intensive volume shrinkage induced by the dehydration and oxidation of the polymers [4-6]. The electro-spraying process with the preceramic slurry can produce desirable pore structure but not the particle size, so it cannot be used alone to prepare desirable thermal spray feedstock.

To solve such a problem, the non-solvent induced phase separation is introduced to combine with the electro-spraying process. The non-solvent induced phase separation technique is among the most important and commonly used processes for preparing membranes with a large number of polymeric building blocks [23, 24]. In order to develop a versatile way to manipulate the microstructure of ceramic microspheres, and fabricate high performance thermal barrier coatings by plasma spraying, we developed a simple and efficient technique, i.e. the non-solvent assisted electro-spraying method (ESNP), to prepare ceramic microspheres. The polymeric slurry used in the electro-spray processing includes a polymer, a guest solvent and ceramic powders. The resulting asymmetric membranes consist of a thin top layer and a porous sublayer that often contains large void spaces or macrovoids. These macrovoids may exhibit different morphologies (i.e. finger-like or sponge-like) depending on the phase separation kinetics and thermodynamics [24]. The ESNP particles are subsequently heat treated to eliminate its polymeric component. The effects of the electro-spray processing parameters and the jet nozzle diameter on the mean size, size distribution, morphology and microstructure of the obtained ESNP microsphere are investigated. The sintered ESNP microspheres were used to prepare TBCs using the atmospheric plasma spray method and the coatings' microstructure and resistance to sintering were examined.

\section{Experimental procedure}




\subsection{Materials}

Yttria stabilized zirconia (YSZ) powder (7 wt. \% $\mathrm{Y}_{2} \mathrm{O}_{3}$, purity of $99.95 \%, 90 \pm 25$ nm, Jiangxi Fanmeiya Materials Co., Ltd.) was a commercial product. Polyethersulfone (PES, BD-5, Beishide Chemical Reagent Factory), N-methyl-2-pyrrolidone (AR Grade, purity of 99\%, GuanghuaSci-Tech Co., Ltd.) and polyvinylpyrrolidone (PVP, K30, Sinopharm Chemical Reagent Co., Ltd.) were used as the polymer binder, the solvent and additive respectively to prepare the spinning solution. Deionized water was used both as internal and external coagulant.

\subsection{Electro-spraying processing}

The ceramic powder was added into N-methyl-2-pyrrolidone (NMP) solvent, well homogenized by applying ultrasonic treatment for $20 \mathrm{~min}$. Then PES was added into the suspension which was thermostated at $50{ }^{\circ} \mathrm{C}$ and stirred for $8 \mathrm{~h}$ to achieve a homogenous slurry with a viscosity of about $11300 \mathrm{mPa} \cdot \mathrm{s}$. The weight ratio of the ceramic powder, NMP and PES were 3: 6: 1. The homogenous slurry was subsequently degassed under vacuum for $30 \mathrm{~min}$ to remove dissolved gases. The degassed slurry was loaded into a plastic syringe connected to a metallic nozzle for electro-spray processing. The home-made device set-up was shown in Fig.1. It consists of a stainless-steel nozzle with a tube diameter of $0.3 \sim 1.4 \mathrm{~mm}$. The jet nozzle was coupled to a high voltage supply and held in a rubber mold. The operating voltage was in the range of $10 \sim 20 \mathrm{kV}$. Polymeric slurry was supplied to the nozzle at a controlled flow rate $(2.0 \sim 7.0 \mathrm{ml} / \mathrm{min})$ using a specially designed Harvard syringe pump (Harvard Apparatus Ltd., Edenbridge, UK). A tap-water bath in a metal container was used to collect electro-sprayed droplets, where the droplets consolidated into spherical particles instantaneously instead of forming aggregates. The obtained ESNP droplets were immersed in another fresh water bath for $36 \mathrm{~h}$ to complete the phase inversion. Then solidified ESNP droplets were removed from the water bath and dried at room temperature for $24 \mathrm{~h}$. Finally, the dried ESNP droplets were sintered at $1250{ }^{\circ} \mathrm{C}$ for $4 \mathrm{~h}$ in a muffle furnace to burn out organic materials and achieve proper strengths. 

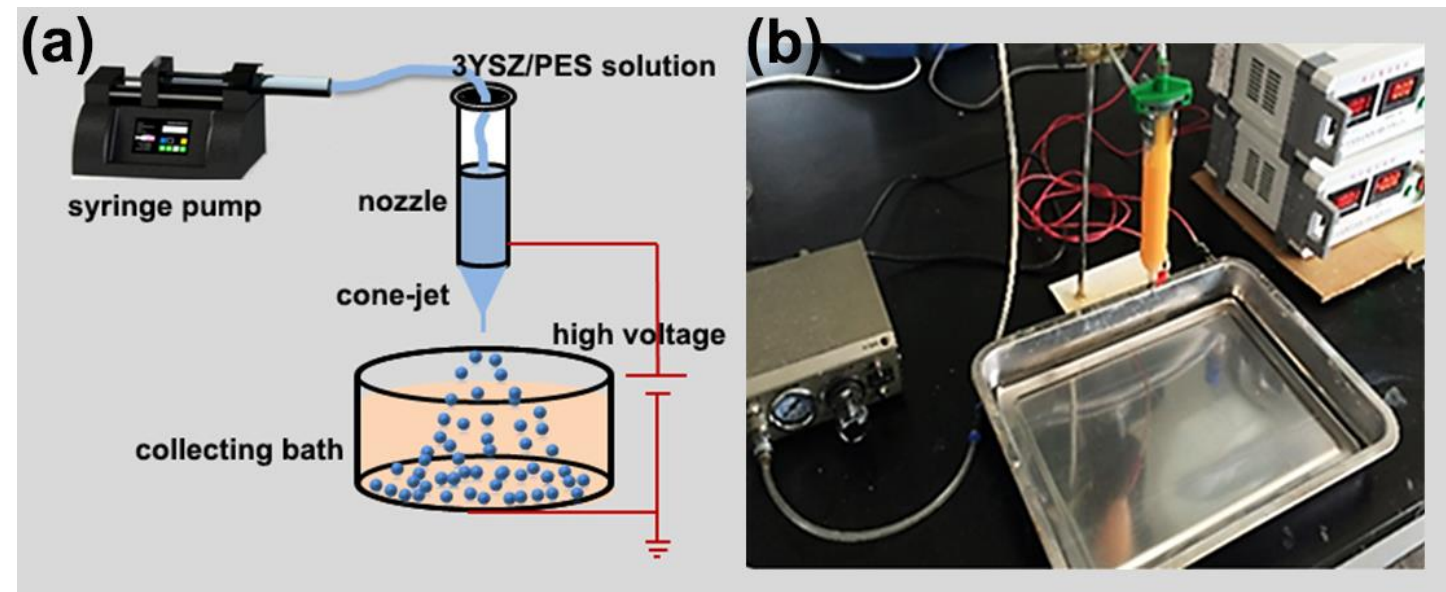

Fig.1 (a) the schematic diagram and (b) a photo of the home-made electro-spraying apparatus for the microparticle preparation.

\subsection{Preparation and test of ceramic coatings}

Ceramic coatings of a thickness of $350 \pm 50 \mu \mathrm{m}$ were prepared by air plasma spraying system on commercial Hastalloy $\mathrm{X}$ alloy plates using either a commercial YSZ powder (HOSP, 7 8 wt. $\% \mathrm{Y}_{2} \mathrm{O}_{3}$, Oerlikon Metco 204B-NS) or home-made ESNP YSZ microspheres. The two powders used had the same size range of $20 \sim 70$ $\mu \mathrm{m}$ as controlled by a sieving procedure. $24 \mathrm{~h}$ furnace thermal cycling of the coatings prepared was conducted, which consists of a heating-up period to $1150{ }^{\circ} \mathrm{C}$ (taking 10 min), a dwelling period at $1150{ }^{\circ} \mathrm{C}(23.5 \mathrm{~h})$, and air quench $(20 \mathrm{~min})$. The $\mathrm{TBC}$ failure was defined as approximate $10 \%$ visible delamination.

\subsection{Morphology, microstructure and phase characterization}

Scanning electron microscopy (SEM, NovaNano-430FEG, FEI, Netherlands) was used to characterize the microstructure of the as-received and polished surfaces/cross sections of the samples. For the cross section observation, the as-sintered ESNP spheres were embedded in epoxy and ground using the conventional metallographic approach to their middle plane to form a half sphere. An optical microscope (BX51M, Olympus, Japan) was used to observe the geometry of green ESNP particles (the particles haven't been heat treated) and sintered ESNP spheres. The mean size of the 
green ESNP particles and sintered ESNP spheres were calculated from measuring at least 150 random individual particles or spheres. The bulk porosity of the sintered ESNP spheres was measured using Archimedes' method [25]. The local porosity and pore size of the sintered ESNP spheres were estimated by analyzing their SEM images by using a free image software (Image J-1.43, National Institutes of Health, US). X-ray diffraction (X' Pert PRO MPD, Panalytical, Netherlands) using Cu-K $\alpha$ operated at $40 \mathrm{kV}$ and $40 \mathrm{~mA}$ was used for phase analysis.

\section{Results and discussion}

With appropriate processing parameters of the electro-spraying, a stable cone-jet can be achieved that yielding particles through jet break up (as shown in Fig.1). There exists a critical solid loading (polymer and YSZ powder) where the particles sprayed were in an intermediate state between disk/donut shapes and fibers. As the solid loading was in the critical range (60 wt. \%), spherical morphology dominated the particles prepared due to the high surface tension and low viscosity of the polymer solution with ceramic powder compared with the pure polymeric solutions [16-18].

\subsection{Morphology and phase composition of sintered ESNP YSZ microspheres}

The droplets produced were collected in a water bath (Fig.1), where consolidation of the droplets occurred as the result of mass exchange between solvent (NMP) and non-solvent (water). The completely solidified ESNP particles were subsequently sintered at $1250{ }^{\circ} \mathrm{C}$ for $4 \mathrm{~h}$ to burn out the polymeric constituents and achieve usable powder strength. Fig.2 shows the scanning electron micrographs of the sintered ESNP YSZ microspheres. The obtained products had diameter of $30 \sim 70 \mu \mathrm{m}$ with tetragonal phase. There were a large number of nanometer sized pores on the outer surface of the sintered ESNP microspheres, while larger finger-like voids with length in tens of micrometers range occupied its porous interior. The finger-like voids of the sintered ESNP microspheres were inherited from the green ESNP particles of which the special internal structure was achieved by the non-solvent induced phase separation 
process [13]. The ESNP method is also able to produce microspheres using other refractory-oxide ceramic materials as described previously [26].
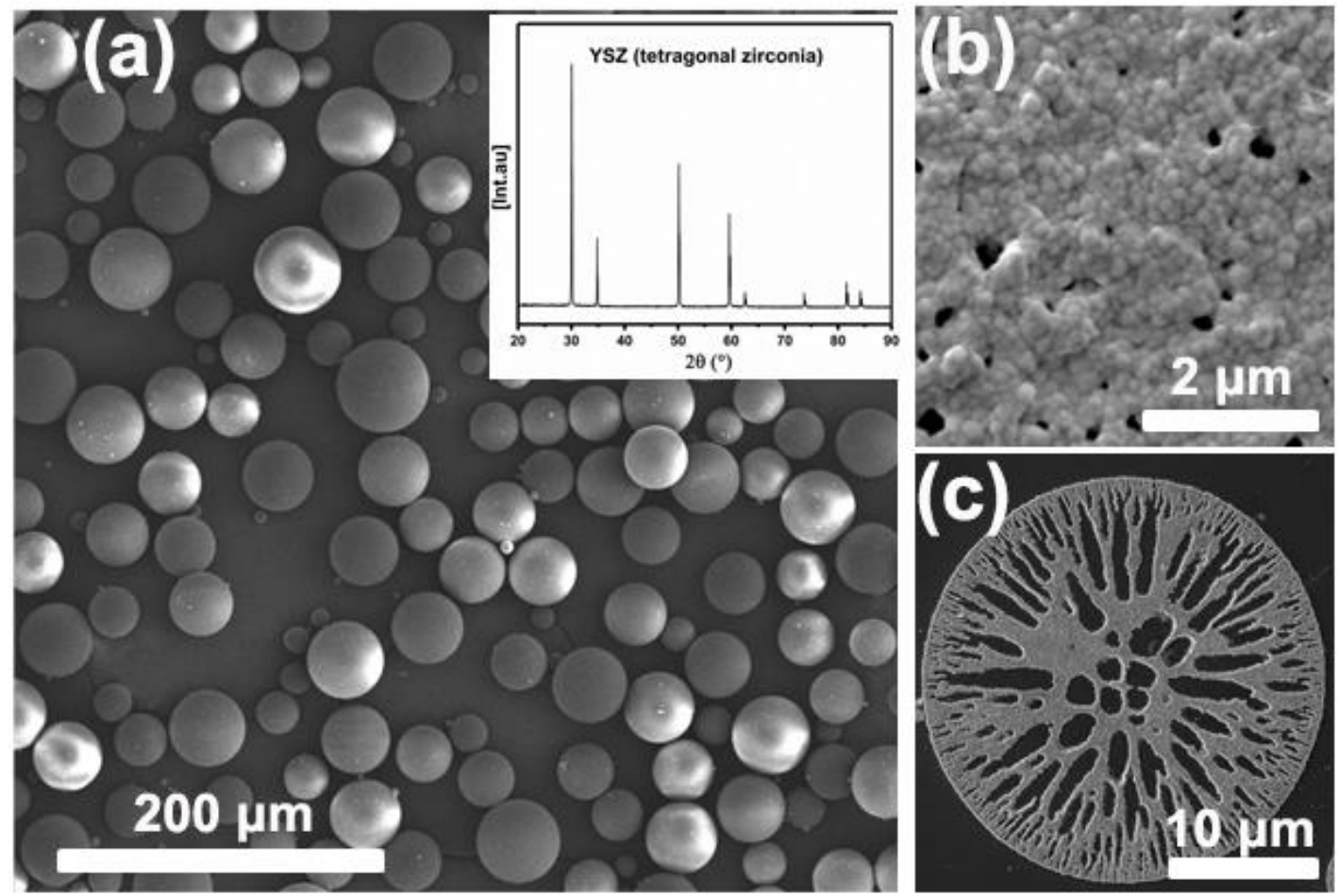

Fig.2 SEM micrographs showing (a) surface morphologies, (b) the outer surface and (c) the polished cross section of sintered ESNP YSZ microspheres prepared by ESNP method. The inset in Fig.2 (a) represents the XRD pattern of the sintered ESNP YSZ microspheres

\subsection{Effects of processing variables on the particle size and distribution}

The effects of key parameters such as the flow rate $(Q)$, the applied voltage $(V)$, the distance between the jet nozzle and the surface of the receiving bath $(H)$ on the particle size of the electro-sprayed polymeric particles have been demonstrated in the literature [16-23]. In this work, the three processing variables $Q, V, H$ as well as the jet nozzle diameter $(D)$ were studied their effects on the mean size $\left(\mathrm{D}_{50}\right)$ and size distribution of the ESNP green particles. Fig.3 (a)-(c) show the mean particle size $\left(\mathrm{D}_{50}\right)$ and particle size range $\left(\mathrm{D}_{10}\right.$ and $\left.\mathrm{D}_{90}\right)$ as a function of $Q, V$ and $H$, respectively. Increasing $Q$ and $H$, or decreasing $V$ resulted in an increase in the mean size, which was in agreement with the prediction of particle size for pure polymeric solution sprayed in the cone-jet mode $[17,18]$. According to the principle of mass 
conservation, the green ESNP particle size is determined by the droplet size sprayed. The continuous slurry thread changes into droplets when the electrical force imposed is greater than the surface tension acting on the tip of the Taylor cone of the slurry. The original droplets are thus inherently unstable and eventually break up into a number of primary droplets and a number of secondary droplets or satellites [20,27]. Therefore, the dependence of the droplet size on processing parameters followed the scaling law developed by Hartman \& Brunner [28], where the droplet size is proportional to $Q$, while inversely proportional to the spray current that can be derived from $H$ and $V$ in our case. However, the flow rate effect did not follow precisely with the scaling law by $\mathrm{H}$ and $V$. The ESNP particles produced at flow rates $1.9 \mathrm{ml} / \mathrm{min}$ and $3.6 \mathrm{ml} / \mathrm{min}$ showed a similar $\mathrm{D}_{50}$ value $(75 \mu \mathrm{m}$ and $90 \mu \mathrm{m})$. Particularly, the $\mathrm{D}_{10}$ value of $50 \mu \mathrm{m}$ of the green ESNP particles appeared in the products prepared at the flow rate of $3.6 \mathrm{ml} / \mathrm{min}$. This might be partly because the high deviation in the particle size measurements, but also due to the confounding effect of the processing variables.
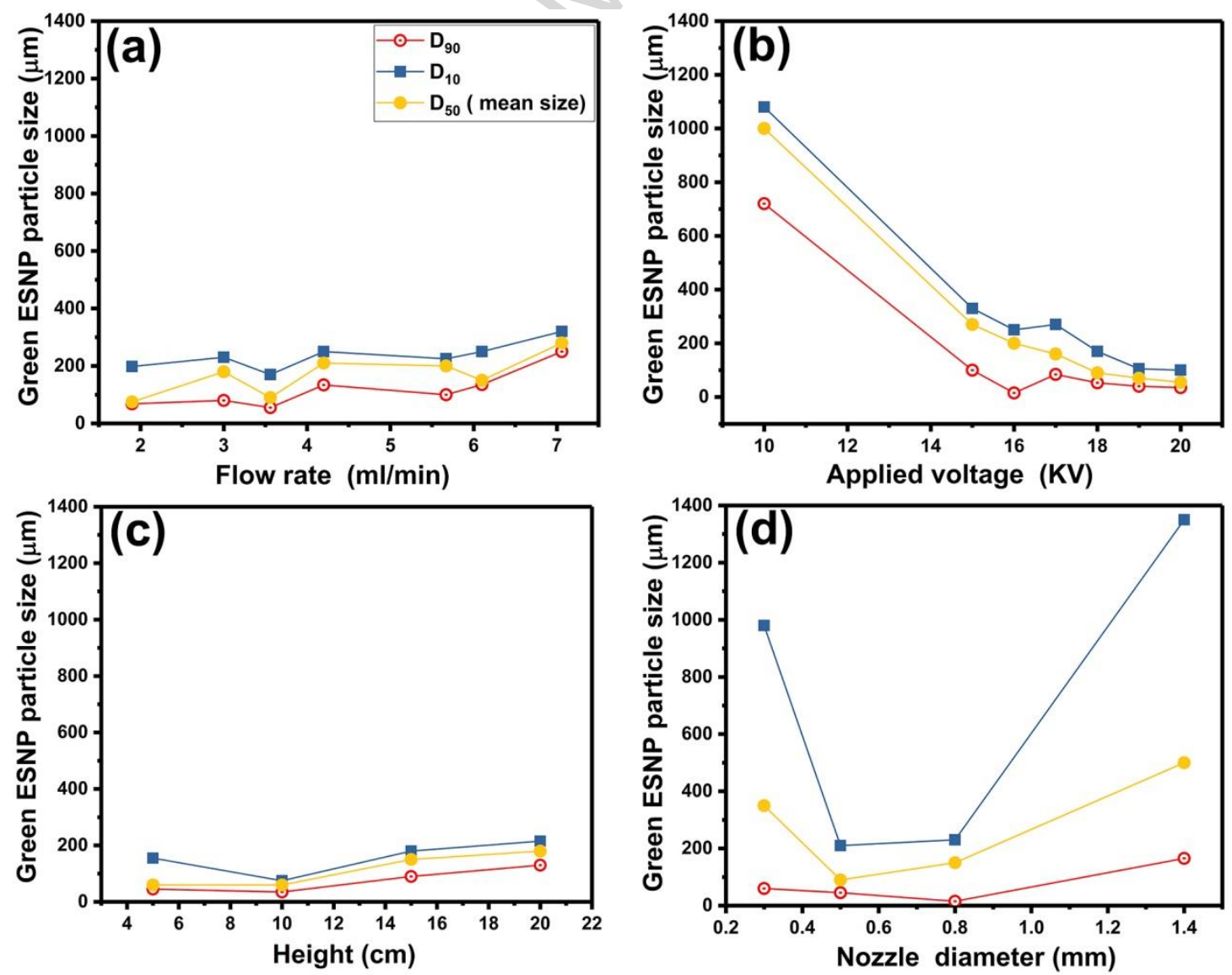
Fig.3 The $D_{50}, D_{10}$ and $D_{90}$ of the green ESNP particles at function of (a) flow rate, (b) applied voltage, (c) distance between needle tip and the water bath and (d) nozzle diameter.

The applied voltage $V$ showed the most significantly affected the mean size of the green ESNP particles investigated, the $\mathrm{D}_{50}$ values decreasing from $\sim 1000$ to $\sim 100 \mu \mathrm{m}$ with the increasing voltage. Higher $V$ and/or shorter $H$ leading to smaller ESNP particles that is due to the greater electric field intensity acting on the jet of the slurry. In electrohydrodynamic processing, the stable cone-jet mode is usually essential for the preparation of fine particles within a narrow size range $[16,27,28]$. The electric conductivity of the polymeric slurry with YSZ powders was pretty low compared to the pure polymeric slurry in literatures [16-18, 20-23], therefore, it was easier to achieve stable jets at the applied voltage investigated. The $H$ should be long enough for the solvent evaporation and the polyethersulfone solidification to proceed to a certain extent, otherwise the droplets might be deformed into elliptical particles instead of staying spheres, as shown in Fig.4. It was also found that increasing the fall height or lowering the applied voltage would increase the dispersion of the green ESNP particles, which might be due to the better surface solidification of flying droplets induced by the solvent volatilization.
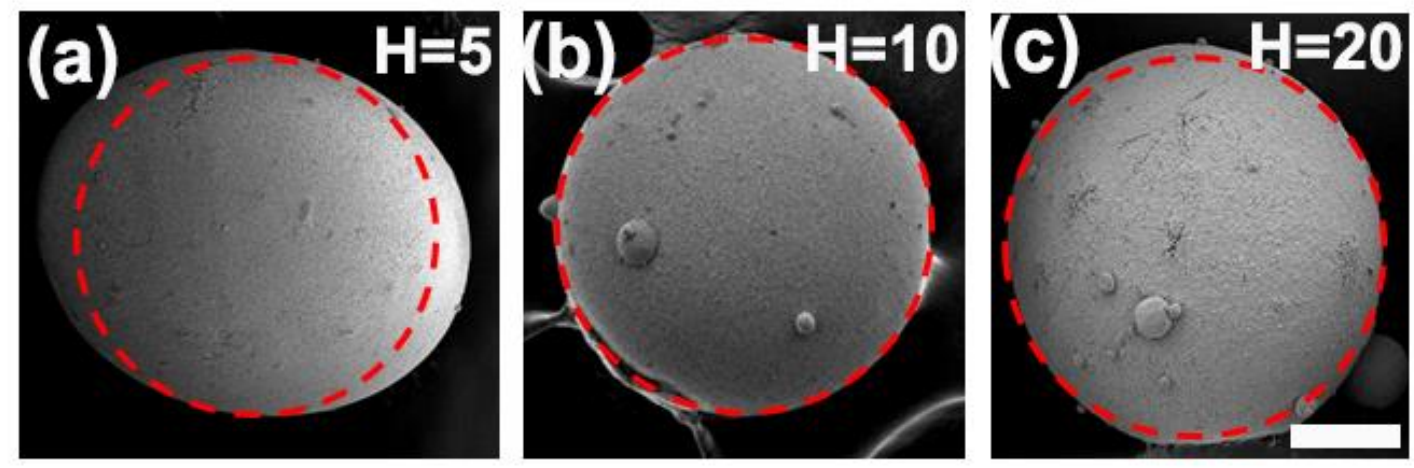

Fig.4 The effect of distance between the nozzle and the surface of the receiving bath $(H)$ on the size and shape of ESNP ceramic particles $(D=0.5 \mathrm{~mm}, Q=3.6 \mathrm{ml} / \mathrm{min}, V$ $=20 \mathrm{kV}$ ). (a) $\mathrm{H}=5 \mathrm{~cm}$, (b) $\mathrm{H}=10 \mathrm{~cm}$ and (c) $\mathrm{H}=20 \mathrm{~cm}$. The scale bar of the SEM images is $20 \mu \mathrm{m}$ and the red dotted lines represent an incircle of the particle. 
The mean size of the ESNP particles determined by the droplet size which is also affected by the nozzle diameter $(D)$ apart from the three processing parameters investigated. Fig.3 (d) shows that the mean size of the green ESNP particles is parabolic to the $D$, with minimum particle size obtained in the $D$ range of $0.5 \sim 0.8$ $\mathrm{mm}$. The size distribution of green ESNP particles was significantly affected by the $D$ values, as shown in Fig.5. The span value was calculated by using the formula $\left(D_{90}-D_{10}\right) / D_{50}[29,30]$. When $D$ was between $0.5 \mathrm{~mm}$ and $0.8 \mathrm{~mm}$, the span value decreased from $\sim 2.5$ to the $\sim 1.5$. Electro-spraying has a number of stable spray modes which include low frequency pulsations, high frequency pulsations, steady cone-jet, ramified-jet and the spindle mode [20-23, 27, 28]. The spray regime characteristics depend on the jet nozzle diameter and the liquid conductivity. The stable cone-jet mode, occurring within a rather narrow range of flow rates and voltages, can theoretically produce uniform-sized droplets. Therefore, it was inferred that the steady cone-jet mode of electrospray was achieved as the $D$ value falls between $0.5 \mathrm{~mm}$ and $0.8 \mathrm{~mm}$ at the given processing window of $Q=3.6 \mathrm{ml} / \mathrm{min}, V=20 \mathrm{kV}$ and $H=10 \mathrm{~cm}$. 


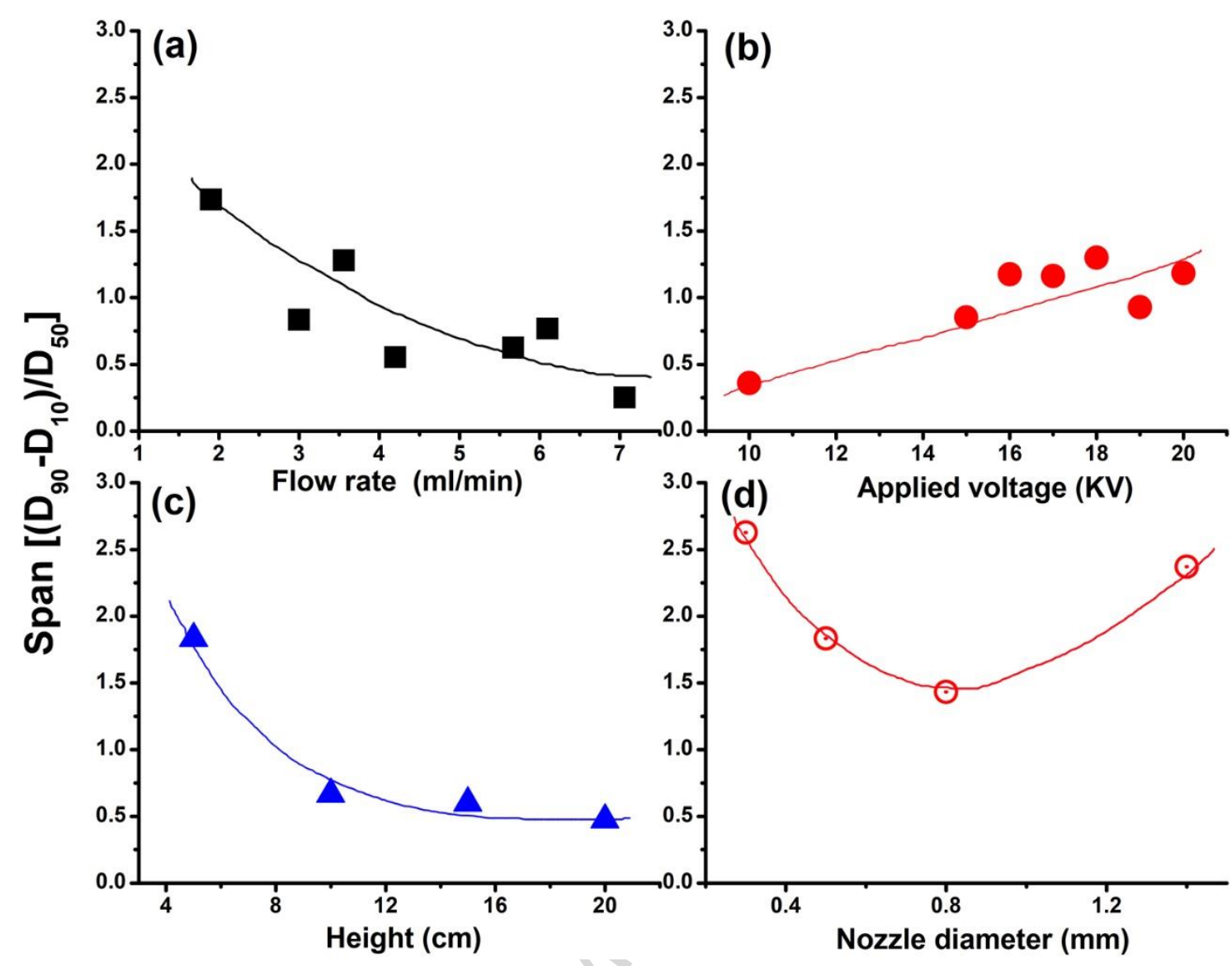

Fig.5 The effects of processing parameters on the particle size distribution (span), (a) flow rate, (b) applied voltage, (c) distance between needle tip and the water bath and (d) nozzle diameter.

\subsection{Dependence of ESNP sphere's internal structure on the sphere diameter}

The green ESNP particles were sintered at $1250{ }^{\circ} \mathrm{C}$ for $4 \mathrm{~h}$ with a heating rate of $5{ }^{\circ} \mathrm{C} / \mathrm{min}$, followed by furnace cooling to ambient temperature. The specific internal structure of the ESNP particles was retained after the sintering, as shown in Fig.6. The ESNP microspheres consisted of an asymmetric porous structure which has a thin sponge-like shell covering the core which may include finger-like macrovoids and/or cavities. The mass exchange between the residual solvent (NMP) in the ESNP droplet and the non-solvent (water) is accounted for formation of the pores and other internal structures of the ESNP YSZ spheres. According to the pore morphologies, the ESNP YSZ spheres were classified into three types (namely, type I, II and III) shown in the schematic images of Fig.6. The ESNP YSZ spheres had three different size ranges, $\sim 1$ 
mm (see Fig.6 (a)-(b)), 200 $\mu \mathrm{m}$ (see Fig.6 (c)-(f)) and 50 $\mu \mathrm{m}$ (see Fig.6 (g)-(i)). The internal structure of the ESNP YSZ spheres is affected by the diameter of the green ESNP particle. The mechanism proposed for the ceramic hollow fiber membranes may explain the relationship between particle size of the ESNP products and its internal structure $[24,25]$. Membranes prepared by using slow polymer precipitation rates tend to have sponge-like morphologies, which is the case in the large sized ESNP droplets. On the other hand, membranes produced with fast precipitation rates had large "finger-like" macrovoids in the substructure, which preferentially occurred in the small sized ESNP droplets. The longer the mass exchange distance (namely, the radius of ESNP droplets), the slower the polymer precipitation rate [24]. In this case, millimeter sized ESNP droplets have slower precipitation rate and tend to produce YSZ spheres with a dense core, while for droplets with diameter of several hundreds of micrometers, the formation of porous interior is preferred.

Besides, local variation in the solid loading of the polymer solution with YSZ powders due to gravity-induced segregation might also affect its internal structure [18, 28]. Sedimentation of the polymeric slurries of YSZ/PES was observed during the electrospray processing, which depended on the electro-spraying duration and solid loading of YSZ powder. The most severe sedimentation was found at the flow rate of $1.2 \mathrm{ml} / \mathrm{min}$, which would affect the droplet size and final particle size as well as the particles' microstructure. 

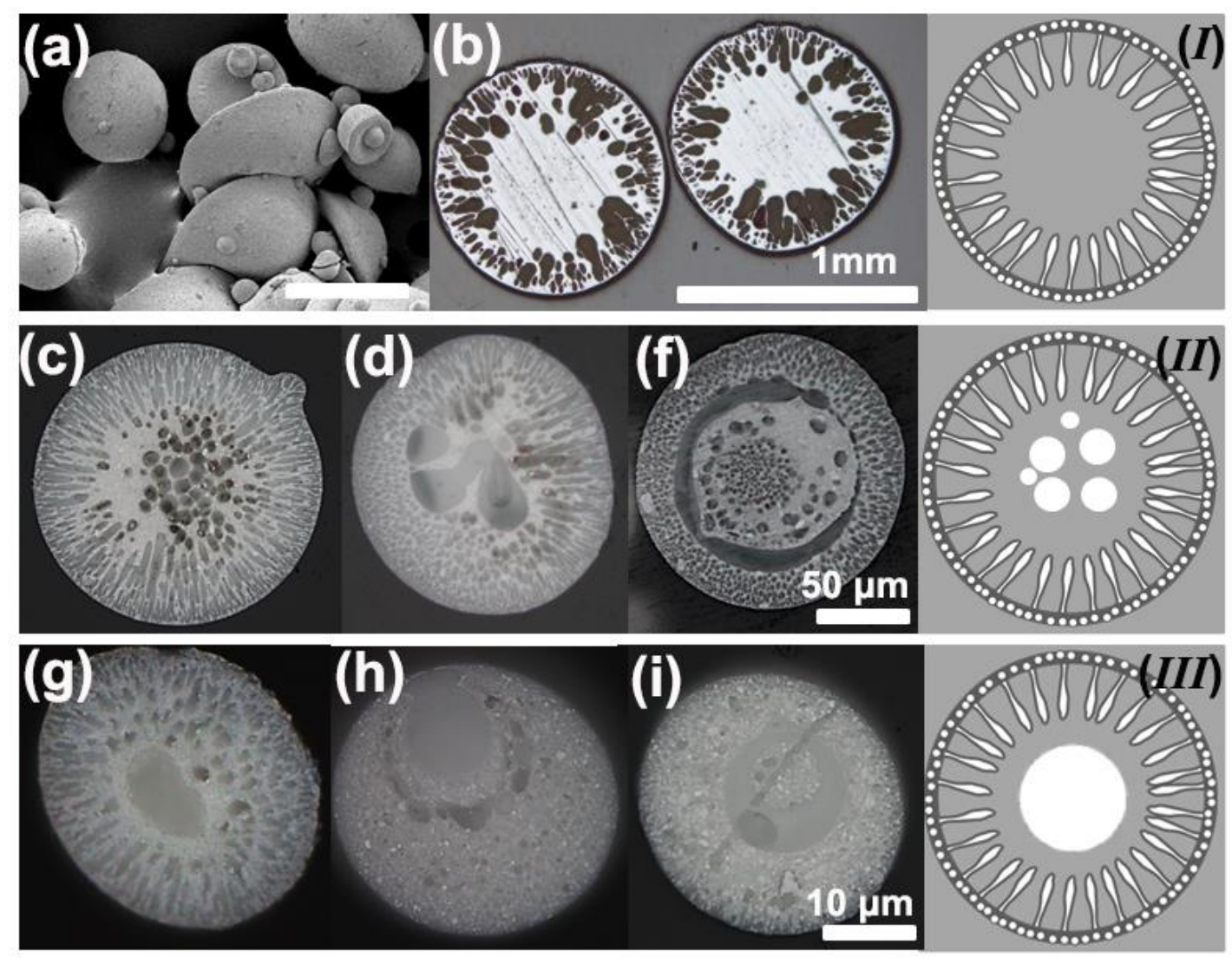

Fig.6 Optical micrographs of polished cross-sections of the sintered ESNP YSZ spheres. (a) The sintered particles with different morphologies and diameters (the scale bar is $2 \mathrm{~mm}$ ), (b) the millimeter sized spheres with type I microstructure, (c)-(f) the hundreds of micrometers sized spheres with type II microstructure, and (g)-(i) the tens of micrometers sized spheres with type III microstructure.

\subsection{Microstructure of coatings prepared using the ESNP YSZ microspheres}

YSZ powders within the size range of $20 \sim 70 \mu \mathrm{m}$ were used for coating preparation by thermal spraying. SEM images for polished cross sections of YSZ coatings were shown in Fig.7. Reference coatings were prepared using commercial HOSP powder shown in Fig.7 (a). The HOSP powders are hollow spheres with a dense shell, having $>90 \%$ porosity $[5,6]$. The porosity of the ESNP microspheres was $45 \pm 2.9 \%$ (measured by Archimedes principle), while the porosity of the thin spongy shell was $\sim 15 \%$ (estimated by Image $\mathrm{J}$ software). The $\sim 10000{ }^{\circ} \mathrm{C}$ flame of the atmospheric plasma spray jet destroyed the microstructure of the HOSP powders as expected, resulting in a typical splat structure (tens of micrometers in diameter) in the 
coatings with an overall porosity of $13.5 \pm 1.2 \%$, as shown in Fig.7 (a). The splat structure was not beneficial to the in plane modulus of TBCs, owing to its low strain tolerance [11-14]. Fig.7 (b)-(c) showed the polished cross section of a coating made from the ESNP YSZ microspheres. For the coatings sprayed using the sintered ESNP YSZ spheres, an overall porosity of $17 \pm 1.0 \%$ was achieved, and the coatings contain both the typical splat structure and a certain amount of partially fused ESNP YSZ microspheres with their initial microstructure remained.

The partially unfused microspheres showed crescentic shapes that were caused by plastic deformation during the spraying, occupying $\sim 20 \%$ area of the deposited coatings. To evaluate the ESNP coatings' resistance to long-term sintering [5, 11, 14], 24-hours furnace thermal cycling was conducted, which consists of 10-minute heating up to $1150{ }^{\circ} \mathrm{C}$, then dwelling at $1150{ }^{\circ} \mathrm{C}$ for $23.5 \mathrm{~h}$ and followed by a $20 \mathrm{~min}$ air quench. After 7 cycles $(168 \mathrm{~h})$, the coatings made from the HOSP powder spalled off from the underlying metals, while the ESNP coatings kept adhered to the substrates after 28 cycles $(600 \mathrm{~h})$, as shown in Fig.7 (d). It was also found that some asymmetric finger-like voids of the starting ESNP microspheres (highlighted by a red circle) remained in the coating after 28 cycles.

Even after sintering at $1500{ }^{\circ} \mathrm{C}$ for $4 \mathrm{~h}$, the ESNP microspheres' internal structure still preserved highly porous and far away from densification, including the finger-like macrovoids of tens of micrometers and finely dispersed nanosized pores, as shown in Fig.8. The results implied that such pores cannot be eliminated during long term sintering, although the nano particles have a tendency to sintering and densification. Therefore, compared with the HOSP coating, the ESNP coating has a higher porosity, thus may achieve lower thermal conductivity. The increased population of micrometer-sized pores could also improve the strain tolerance and life time of the as-sprayed coating reported in our unpublished results [31]. According to the critical coordination number theory [32-34], if a pore is surrounded by too many grains (usually >10) [33], then the free energy gain due to the extension of the grain-boundaries into the pore outbalances the free energy loss due to the elimination $16 / 25$ 
of the pore surface, thus pores will be stable in the structure and there will be a limiting density even though removal of the pores would lower the energy of the system. The finger-like voids with tens of micrometers of the sintered ESNP YSZ spheres are typically surrounded by more than 24 grains (see Fig.S1 in Supplementary data).
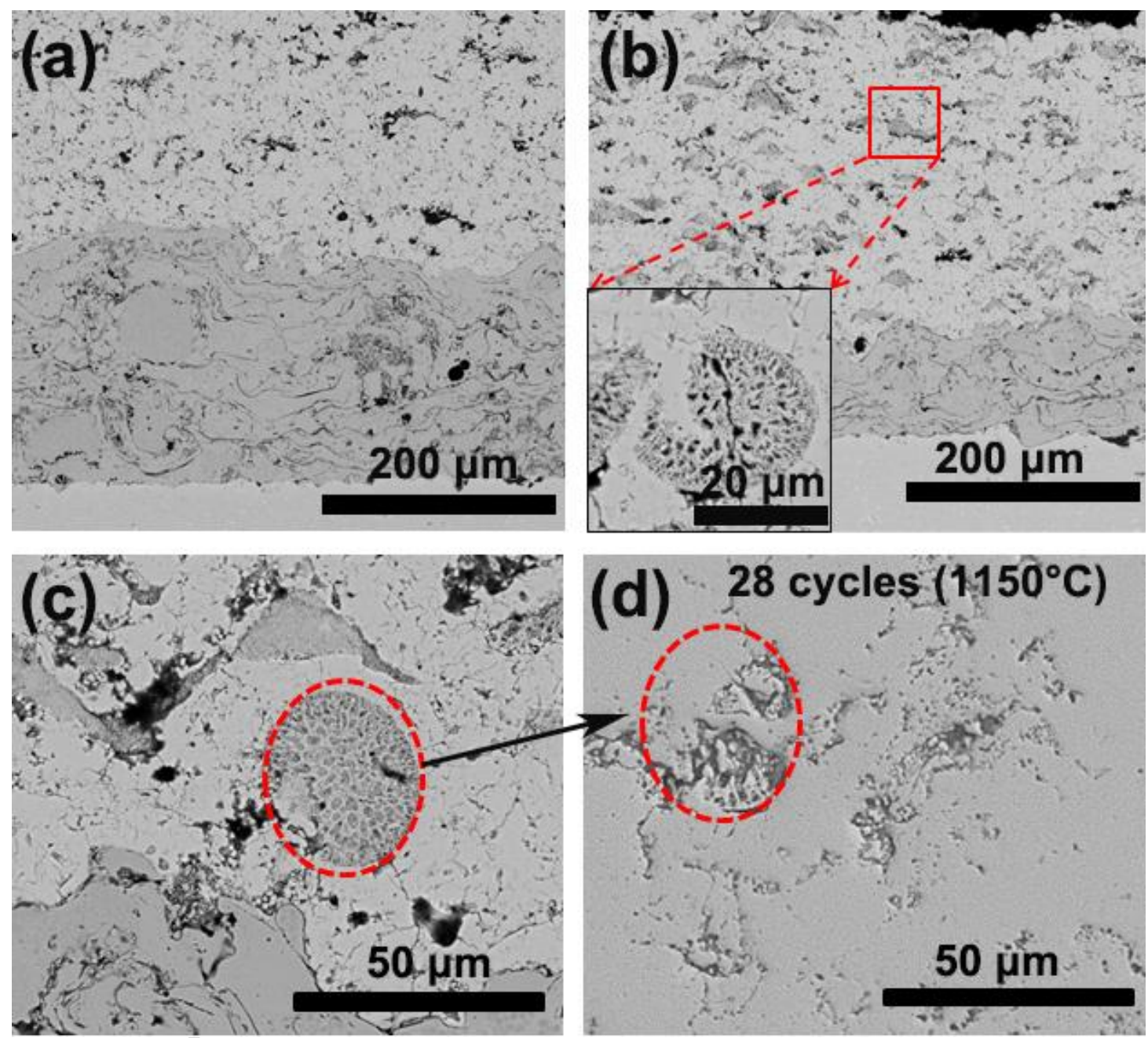

Fig.7 SEM micrographs of polished cross sections of the coatings on metal substrates prepared by atmospheric plasma spraying method, (a) using the commercial HOSP feedstock, (b) the ESNP YSZ microspheres; SEM micrographs of the polished cross sections of (c) an as-received ESNP coating, and (d) the same sample heat treated for 28 cycles at $1150{ }^{\circ} \mathrm{C}$ in a muffle furnace. 

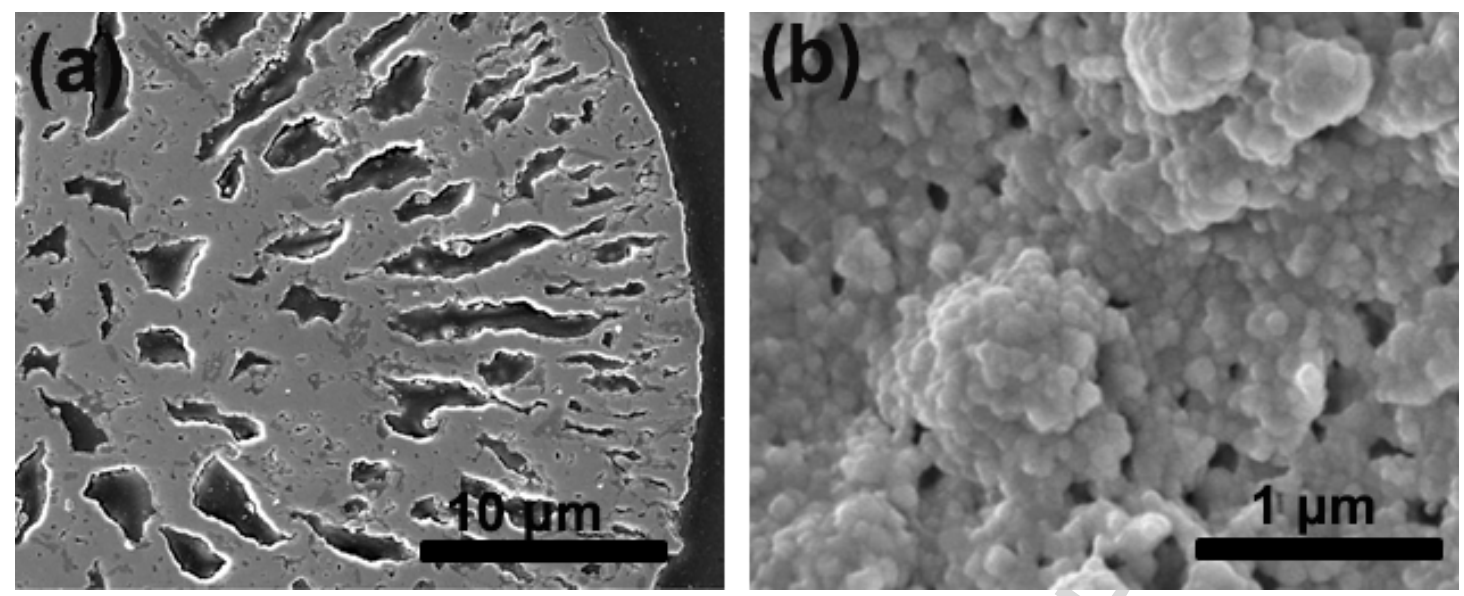

Fig.8 SEM micrographs of (a) polished cross section and (b) the internal structure of a finger-like void of the ESNP YSZ microsphere sintered for $4 \mathrm{~h}$ at $1500{ }^{\circ} \mathrm{C}$.

\section{Summary}

Micrometer-sized yttria-stabilized zirconia (YSZ) particles were prepared by the combined electro-spraying and non-solvent induced phase separation (ESNP) method, in which the slurry droplets were solidified as contacting with the water bath (non-solvent). Subsequent sintering was carried out to obtain porous hollow ESNP YSZ microspheres. The morphology, micro structure, particle size and size distribution could conveniently be manipulated by adjusting the applied voltage and nozzle diameter. The sintered ESNP microspheres have a core either with porous structure of finger-like voids or just hollow that is covered by a thin spongy shell. The thin shell's porosity was $\sim 15 \%$ which was a quarter of the sintered ESNP sphere's bulk porosity. In comparison to coatings prepared by using the commercial feedstock, the coatings made from ESNP microspheres showed higher resistance to sintering, owing to the unique microstructure of the microspheres. The novel ceramic granulation method provides a way to introduce a unique microstructure into thermal sprayed coatings, thus could be an approach to improve the performance of plasma sprayed coatings. 


\section{Acknowledgements}

This work was supported by the National Natural Science Foundation of China (Grant No. 51402058), the research fund of Shanghai Committee of Science and Technology (Grant No. 14ZR1422900), and CNPEC financial support (Grant No. 007-EC-B-2014-C83-PS10-00065).

\section{References}

[1].N. P. Padture, M. Gell and E. H. Jordan, Thermal barrier coatings for gas-turbine engine applications, Science 296 (2002) 280-284.

[2].D. R. Clarke, and C. G. Levi, Materials design for the next generation thermal barrier coatings, Ann. Rev. Mater. Sci. 33 (2003) 383-417.

[3].J. S. Wallace, J. Ilavsky, Elastic modulus measurements in plasma sprayed deposits, J. Therm. Spray Tech. 7(4) (1998) 521-526.

[4].A.J. Allen, J. Ilavsky, G.G. Long, J.S. Wallace, C.C. Berndt, H. Herman, Microstructural characterization of yttria-stabilized zirconia plasma-sprayed deposit using multiple small-angle neutron scattering, Acta Mater. 49 (2001) $1661-1675$.

[5].Batur Ercan, Keith J. Bowman, Rodney W. Trice, Hsin Wang, Wally Porter Effect of initial powder morphology on thermal and mechanical properties of stand-alone plasma-sprayed 7 wt.\% Y2O3-ZrO2 coatings, Mater. Sci. Eng. A $435-436$ (2006) 212-220

[6].Pei-Hu Gao, Guan-Jun Yang, Si-Ting Cao, Jian-PingLi, ZhongYang, 
Yong-Chun Guo, Heredity and variation of hollow structure from powders to coatings through atmospheric plasma spraying, Surf. Coat. Technol. 305 (2016) $76-82$

[7].S. Sampath, U. Schulz, M.O. Jarligo, S. Kuroda, Processing science of advanced thermal-barrier systems, Mate. Res. Soc. Bull. 37 (2012) 903-910.

[8].A. Kulkarni, Z. Wang, T. Nakamura, S. Sampath, A. Goland, H. Herman, J. Allen, J. Ilavsky, G. Long, J. Frahm, R.W. Steinbrech, Comprehensive microstructural characterization and predictive property modeling of plasma-sprayed zirconia coatings, Acta Mater. 51 (2003) 2457-2475.

[9].G. Bertrand, P. Bertrand, P. Roy, C. Rio, R. Mevrel, Low conductivity plasma sprayed thermal barrier coating using hollow psz spheres: Correlation between thermophysical properties and microstructure, Surf. Coat. Technol. 202(10) (2008) 1994-2001.

[10].W.G. Chi, S. Sampath, H. Wang, Microstructure-thermal conductivity relationships for plasma-sprayed yttria-stabilized zirconia coatings, J. Am. Ceram. Soc. 91(8) (2008) 2636-2645.

[11].K.W. Schlichting, N. P. Padture, E. H. Jordan, and M. Gell, Failure modes in plasma-sprayed thermal barrier coatings, Mater. Sci. Eng. A 342 (2003) 120-130.

[12].M. Karger, R. Vassen, D. Stover, Atmospheric plasma sprayed thermal barrier coatings with high segmentation crack densities: Spraying process, microstructure and thermal cycling behavior, Surf. Coat. Technol. 206(1) 
(2011) 16-23.

[13].G. Dwivedi, V. Viswanathan, S. Sampath, A. Shyam, E. Lara-Curzio, Fracture Toughness of Plasma-Sprayed Thermal Barrier Ceramics: Influence of Processing, Microstructure, and Thermal Aging, J. Am. Ceram. Soc. 97(9) (2014) 2736-2744.

[14].A. Kulkarni, A. Vaidya, A. Goland, S. Sampath, H. Herman, Processing effects on porosity-property correlations in plasma sprayed yttria-stabilized zirconia coatings, Materials Science and Engineering a-Structural Materials Properties Microstructure and Processing 359(1-2) (2003) 100-111.

[15].Y.Gao, Y. Zhao, D. Yang, J.Gao, A novel plasma-sprayed nanostructured coating with agglomerated-unsintered feedstock, J. Therm. Spray Technol. 25 (2016) 291-300.

[16].I.G. Loscertales, A. Barrero, I. Guerrero, R. Cortijo, M. Marquez, A.M. Gañán-Calvo, Micro/nano encapsulation via electrified coaxial liquid jet, Science 295(2002) 1695-1698.

[17].X.W. Huang, J.F. Gao, W. Li, H.G. Xue, R.K.Y. Li, Y.W. Mai, Preparation of poly( $\varepsilon$-caprolactone) microspheres and fibers with controllable surface morphology, Mater. Des. 117 (2017) 298-304.

[18].M. Enayati, M.W. Chang, F. Bragman, M. Edirisinghe, E. Stride, Electrohydrodynamic preparation of particles, capsules and bubbles for biomedical engineering applications, Colloids and Surfaces A: Physicochem. Eng. Aspects 382 (2011) 54-164. 
[19].M. Nangrejo, E. Bernardo, P. Colombo, U. Farook, Z. Ahmad, E. Stride, M. Edirisinghe, Electrohydrodynamic forming of porous ceramic capsules from a preceramic polymer, Mater. Lett. 63 (34) (2009) 483-485.

[20].A. Jaworek, A. Krupa, Classification of the modes of EHD spraying, J. Aerosol Sci. 30 (1999) 873-893.

[21].J. Park, M. Hardy, S. Kang, K. Barton, K. Adair, D.K. Mukhopadhyay, C.Y. Lee, M.S. Strano, A.G. Alleyne, J.G. Georgiadis, P.M. Ferreira, J.A. Rogers, High-resolution electrohydrodynamic jet printing, Nat. Mater. 6 (2007) 782-789.

[22].M.D. Paine, M.S. Alexander, K.L. Smith, M. Wang, J.P.W. Stark, Controlled electrospray pulsation for deposition of femtoliter fluid droplets onto surfaces, J. Aerosol. Sci. 38 (2007) 315-324.

[23].G.R. Guillen, Y. Pan, M. Li, E.M.V. Hoek, Preparation and characterization of membranes formed by non-solvent induced phase separation: a review, Ind. Eng. Chem. Res. 50 (7) (2011) 3798-3817.

[24].C.A. Smolders, A.J. Reuvers, R.M. Boom, I.M. Wienk, Microstructures in phase-inversion membranes.1. Formation of macrovoids. J. Membr. Sci. 73 (1992) 259-275.

[25]. Standard Test Method for Water Adsorption, Bulk Density, Apparent Porosity and Apparent Specific Gravity of Fired White ware Products. ASTM C (1999) 373-88.

[26].L. X Yang, D. Peng, C.S Zhao, C. Xing, F. W. Guo, Z.Q. Yao, Y. Z. Liu, X. F. 
Zhao, P. Xiao, Evaluation of the in-depth temperature sensing performance of Eu- and Dy-doped YSZ in air plasma sprayed thermal barrier coatings, Surf. Coat. Technol. 316 (2017) 210-218.

[27].A. Jaworek, A. Krupa, Jet and drop formation in electrohydrodynamic spraying of liquids. A systematic approach, Exp. Fluids 27 (1999) 43-52.

[28].R. P. Hartman, D. J. Brunner, D. M. A. Camelot, J. C. M. Marijnissen and B. Scarleet, Jet break-up in electrohydrodynamic atomization in the cone-jet mode, J. Aerosol Sci. 31(2000) 65-95.

[29].T. Kinnarinen, R.Tuunila, A. Häkkinen, Reduction of the width of particle size distribution to improve pressure filtration properties of slurries, Miner. Eng. 102 (2017) 68-74.

[30].T. A. Ring, 2 - Ceramic Powder Characterization, In Fundamentals of Ceramic Powder Processing and Synthesis, Academic Press, San Diego, 1996, Pages 43-79.

[31].Z. H. Zhou, C. Xing, F. W. Guo, X. Wang, X. F. Zhao, P. Xiao, A highly strain and damage tolerant thermal barrier coating fabricated by elect ro-sprayed zirconia hollow spheres, in preparation for submission, July (2017).

[32].B. J. Kellett, F. F. Lange, Thermodynamics of densification: I, Sintering of simple particle arrays, equilibrium configurations and pore stability and shrinkage, J. Am. Ceram. Soc. 72 (1989) 725-734.

[33].E. B. Slamovich, F. F. Lange, Densification of large pore: I. Experiment, J. Am. Ceram. Soc. 75 (1992) 2498-2508. 
[34].J. Pan, H. N. Ch'ng, A. C. F. Cocks, Sintering kinetics of large pores, Mech.

Mater. 37 (2005) 705-721. 


\section{Highlights}

- Porous hollow ceramic microspheres were prepared by combined electro-spraying and non-solvent induced phase separation.

- The microsphere size decreased from 1000 to $100 \mu \mathrm{m}$ with increasing voltage (10 $\sim 20 \mathrm{kV})$.

- The cone-jet mode of electrospray reached steady as the nozzle diameter varied from 0.5 to $0.8 \mathrm{~mm}$.

- The microstructure of microspheres depends on the solvent amount and exchanging rate between the solvent and non-solvent.

- Coatings prepared using microspheres resist to sintering and exhibit a longer life than commercial powder. 